\title{
The Outcomes of a Two-Stage Otoacustic Emissions / Auditory Brainstem Response Newborn Hearing Screening in Albania 2009-2011
}

\author{
Edlira Beqiri ${ }^{1}$, Sara Beqiri ${ }^{2}$ \\ ${ }^{1}$ Pediatric ENT, UHC"Mother Theresa",Tirana, Albania \\ ${ }^{2}$ St Clare ${ }^{e e s}$ Oxford, UK
}

\begin{abstract}
Universal neonatal hearing screening Project started in Albania for the first time in January 2009. It was made possible by the support of Magis, an Italian $\mathrm{NGO}$, as a grant of Italian government to the Albanian health system. The incidence of permanent congenital hearing impairment (PCHI) is the highest among all the congenital diseases well known worldwide. It ranges from 1-3 hearing impaired children for 1000 births per year. This prevalence increases if we take into account the progressive and acquired hearing losses that continues to rise until the age of 9 years old.The early diagnosis of PCHI is essential in preventing the irreversible consequences in the speech development of the chidren born with this handicap. "use it or lose it"-Sinninger, Doyle\&Moore, 1999. Early interruption of the sensor stimuli in the auditory system, is followed by morphological and functional damage of the neurons. This damage can be prevented only by early stimulation of the auditory system within a sensitive period.
\end{abstract}

Keywords:neonatal hearing screening, hearing impairment, auditory brainstem response, otoacustic emissions.

\section{Introduction}

Universal neonatal hearing screening Project started in Albania for the first time in January 2009. It was made possible by the support of Magis, an Italian NGO, as a grant of Italian government to the Albanian health system.

The incidence of permanent congenital hearing impairment (PCHI) is the highest among all the congenital diseases well known worldwide. It ranges from 1-3 hearing impaired children for 1000 births per year. This prevalence increases if we take into account the progressive and acquired hearing losses that continues to rise until the age of 9 years old.

The early diagnosis of PCHI is essential in preventing the irreversible consequences in the speech development of the children born with this handicap.

“use it or lose it"- Sinninger, Doyle\&Moore, 1999.

Early interruption of the sensor stimuli in the auditorysystem, is followed by morphological and functional damage of the neurons.

This damage can be prevented only by early stimulation of the auditory system within a sensitive period

Recent technological advances have made feasible universal newborn hearing screening and therefore early detection of permanent childhood hearing impairment. Over the past three years, new information has been published on whether early intervention is beneficial, the possibility of harm arising from newborn screening, and its cost. Dramatic progress has been made in the large scale implementation of universal screening in many parts of the western world.

\section{Aim}

The aim of this study was to assess the prevalence of PCHI in Albania.

\section{Material and Methods}

The efficacy of a screening program depends on a well organisedstructure which includes the public administration, health and educational centers taking into account the cost and profit ratio.

The screening should cover the whole population of newborns, because is obvious for everyone who works in this field that selective screening, misses almost half of the babies born with hearing impairment. Half of the children born with any degree of hearing impairment don't fall to any risk group.

For the first time in Albania a UNHS was implemented as a three year project, starting from January 2009 until December 2012. The screening covered the three main cities of Albania; Tirana, Shkodra and Fier. The total birth rate in Albania is 30000-35000 births per year.

We decided to follow the Guidelines of the JCHI to applya two step screen in which an infant who shows, ,no clear response $^{\text {cee }}$ on the initial test undergoes a second test soon after the first.If the second test also shows no clear response, the case is referred for audiologic evaluation. The principal neonatal screening tests are detection of transient evoked otoacoustic emissions (TEOAEs) and auditory brainstem response (ABR) testing. The screen consists of either repetition of one of these tests or sequential use of the two different methods either in all babies or, in other applications, only if the first test gives no clear response.

The tests we use are: 


\section{International Journal of Science and Research (IJSR) \\ ISSN (Online): 2319-7064}

Index Copernicus Value (2013): 6.14 | Impact Factor (2014): 5.611

TEOAE - tension evoked otoacusticemission, It is an objective test for neonatal screening to a level of $30 \mathrm{~dB}$, as OAE's are only observed in ears which are in good physiological condition. TEOAE may be affected by incomplete clearance of fetal middle ear fluid or vernixcaseosa (debris) in the external ear, resulting in referral rates of $5 \%$ to $20 \%$ when screening is performed during the first 24 hours after birth, it lowers day by day in the first week of life to $1.9 \%$ on day 7 .

ABR- auditory brainstem response is an objective test, extracted from ongoing electrical activity in the brain after transmitting sound click stimulus into the baby"s ear throughan headphones. The potentials are recorded via the electrodes placed on the scalp. The resulting recording is a series of waves from I-V. These waves occur in the first 10 miliseconds after the onset of the stimulus.

The ABR is used for newborn hearing screening, auditory threshold estimation, intraoperative monitoring, determining hearing loss type and degree, and auditory nerve and brainstem lesion detection.

The first level: every newborn is tested with TEOAE in the neonatal units of the maternities of Tirana, Shkodra and Fier within the first 3 days of life. This is a quick, automatic and non invasive test. The expected results are "pass" or "refer". If the baby results a "refer" case, he/she will underwent the second step exams such as ABR.

The second level:every "refer" case will be examined by mean of ABR(auditory brainstem response). Another group of newborns which will be submitted to ABR is that is the group that is recovered in the NICU for more than 5 days, because of the great risk for retrocochlear pathologies. This exam is performed in the pediatric ENT department of the UHC"Mother Theresa".

\section{Results}

Universal neonatal hearing screening in Albania started on January 2009 until December 2012.

47341 newborns were tested.

93 babies resulted with bilateral hearing loss after the two steps screening.

85 babies had hearing aids, 8 babies decided to get medical treatment abroad. III

The incidence at the end of the project is 2.1 babies with bilateral hearing impairment per 1000 births / year. (2.1/1000 births )

\begin{tabular}{l|l|l|l|}
\hline RESULTS & $\mathbf{2 0 0 9}$ & $\mathbf{2 0 1 0}$ & $\mathbf{2 0 1 1}$ \\
\hline $\begin{array}{l}\text { TOTAL NUMBER } \\
\text { OF TEAOE }\end{array}$ & 13570 & 16896 & 16875 \\
\hline PASS & $96,2 \%$ & $97,8 \%$ & $97 \%$ \\
\hline $\begin{array}{l}\text { FAIL or REFER } \\
\text { LOST }\end{array}$ & $3,8 \%$ & $2,2 \%$ & $3 \%$ \\
\hline $\begin{array}{l}\text { HEARING } \\
\text { IMPAIRMENT }\end{array}$ & $2,03 \%$ & $1.3 \%$ & $1.36 \%$ \\
\hline
\end{tabular}

\section{Discussion}

Eventhough the expected prevalence was higher, we should take into account some reasons that influenced on it.

- In some cases the families did not accept the screening, and this mainly because of the low cultural or /and intellectual level,

- The nurses were not available making it impossible for the babies to go through the screening.

- Some parents didn ${ }^{\mathrm{e}} \mathrm{t}$ return for the reexaminations of the first or second level.

- The center for the second level exams is located only in Tirana, making it difficult for children from other cities to come and go, for follow up exams.

- We believe that the incidence of bilateral hearing impairment would rise significantly if the screening covered the remote areas of Albania where the socioeconomical and health care level is low.

\section{Conclusions}

The incidence at the end of the project is 2.1 babies with bilateral hearing impairment per 1000 births / year. $(2.1 / 1000$ births)

\section{References}

[1] Newborn hearing screening on infants at risk.Ohl C, Dornier L, Czajka C, Chobaut JC, Tavernier L. Int J PediatrOtorhinolaryngol. 2009 Sep 29.

[2] National Newborn Hearing Screening Program in Turkey: Struggles and implementations between 2004 and 2008. Bolat H, Bebitoglu FG, Ozbas S, Altunsu AT, Kose MR. Int J PediatrOtorhinolaryngol. 2009 Aug 27.

[3] Cost analysis of an Italian neonatal hearing screening programme.Mezzano P, Serra G, Calevo MG; STERN Group. J Matern Fetal Neonatal Med. 2009 Sep;22(9):806-11.

[4] Benefit and pitfalls of newborn hearing screening.Asma A, Wan Fazlina WH, Almyzan A, Han YS, Jamilah AG, Roslin S, Ann MT, Borhan L, Wan Norliana A, Saim L, Rohana J. Med J Malaysia. 2008 Oct;63(4):293-7.

[5] Rehabilitation and outcome of severe profound deafness in a group of 16 infants affected by congenital cytomegalovirus infection.Ciorba A, Bovo R, Trevisi $\mathrm{P}$, Bianchini C, Arboretti R, Martini A. Eur Arch Otorhinolaryngol. 2009 Oct;266(10):1539-46. Epub 2009 Mar 13

[6] [Evaluation of the infants' hearing loss in hearing screening]Xiao S, Liao M, Wu W, Lao L, Gao S, Zhou J, Luo R. Lin Chung Er Bi Yan Hou Tou Jing Wai Ke Za Zhi. 2008 Nov;22(22):1028-31.

[7] Newborn hearing screening and strategy for early detection of hearing loss in infants.Jakubíková J, Kabátová Z, Pavlovcinová G, Profant M. Int J Pediatr Otorhinolaryngol. 2009 Apr;73(4):607-12. Epub 2009 Jan 31 . 